This item was submitted to Loughborough's Research Repository by the author.

Items in Figshare are protected by copyright, with all rights reserved, unless otherwise indicated.

\title{
Application of rapid manufacturing techniques in support of maxillofacial treatment: evidence of the requirements of clinical applications
}

PLEASE CITE THE PUBLISHED VERSION

\section{PUBLISHER}

(C) IMechE / Professional Engineering Publishing

\section{VERSION}

VoR (Version of Record)

\section{LICENCE}

CC BY-NC-ND 4.0

\section{REPOSITORY RECORD}

Chandra, Amit, Jason Watson, J. Holland, Russell A. Harris, and David J. Williams. 2019. "Application of Rapid Manufacturing Techniques in Support of Maxillofacial Treatment: Evidence of the Requirements of Clinical Applications". figshare. https://hdl.handle.net/2134/4563. 
This item was submitted to Loughborough's Institutional Repository (https://dspace.lboro.ac.uk/) by the author and is made available under the following Creative Commons Licence conditions.



For the full text of this licence, please go to: http://creativecommons.org/licenses/by-nc-nd/2.5/ 


\title{
Application of rapid manufacturing techniques in support of maxillofacial treatment: evidence of the requirements of clinical applications
}

\author{
A Chandra ${ }^{1 *}$, J Watson ${ }^{2}$, J E Rowson $^{2}$, J Holland $^{3}$, R A Harris ${ }^{1}$, and D J Williams ${ }^{1}$ \\ ${ }^{1}$ Loughborough University, Loughborough, UK \\ ${ }^{2}$ Department of Oral and Maxillofacial Surgery, Queens Medical Centre, Nottingham, UK \\ ${ }^{3}$ East Midlands NHS Innovations Hub, Nottingham, UK
}

The manuscript was received on 10 November 2004 and was accepted after revision for publication on 21 February 2005.

DOI: $10.1243 / 095440505 X 32300$

\begin{abstract}
The concept of applying rapid manufacturing technology to maxillofacial treatment has been described previously; however, these reports did not take into account the practicality of its actual incorporation into clinical practice. Patents in the field are based on imaging techniques combined with rapid manufacturing, which theoretically lead to reconstruction of faces. Some cases studies reported have dealt with the manufacture of prostheses on the laboratory scale. Here two case studies are reported that used imaging and rapid manufacturing techniques for making an ear prosthesis and a burns mask for two patients. Laser scanning was chosen for imaging and Thermojet printing and fused deposition modelling for rapid manufacturing. Outcomes of the study were threefold: improvement in the process, improvement in patient care, and clinical application of existing technology to healthcare. With further research this technology may aid maxillofacial prosthetists in busy facial clinics, reduce patient clinic time, and improve the final product.
\end{abstract}

Keywords: rapid manufacturing, prostheses, burns splints, maxillofacial treatment

\section{INTRODUCTION}

Many people are affected by some facial deformity which can be congenital (e.g. microtia), acquired (e.g. surgical removal of tumours), or traumatic (e.g. burns). As a person's face is the presentation of that person to the world, the emotional trauma caused by disfigurement to what is conceived as a normal face can be enormous [1]. Rehabilation of the face is most important to carry on a normal life for the patients. Corrective surgery has improved appearance and is capable of restoring lost tissue but it may not be the final answer for many patients because of age, medical condition, surgical skill, or patient preference.

Traditionally any rehabilitation process such as a prosthesis or a burns splint required the maxillofacial

\footnotetext{
* Corresponding author: Healthcare Engineering Group, Wolfson School of Mechanical and Manufacturing Engineering, Loughborough University, University Road, Loughborough LE11 3TU, UK. email: A.Chandra@lboro.ac.uk
}

prosthetist to make exact replicas of the patient's face in stone or wax. In the conventional procedure a facial impression or imprint is taken that results in a moulage or an exact duplication of the patient's face in a stony material [2]. For this process, the patient is seated or made to lie down in a comfortable position in order to take the impression. Sitting in an upright posture is often preferred as gravity affects the soft tissues on the face and the impression can be consequently distorted. Hair on the patient's head is covered with gauze 'stockinet' and eyebrows, eyelashes, and any other facial hair must be covered with cold cream or petroleum jelly to prevent alignate entrapment. Moustaches or beards also need special coating in case they cause the impression material to tear. Care must be taken to ensure that the patient can breathe as comfortably as possible during the impression stage. Usually a breathing tube is placed in the mouth. Often there is a need for the patient and the anaplastologist to establish a way of communicating with hand signals to indicate discomfort. 
The process begins with the patient assuming a natural relaxed facial expression as in sleep. The alignate is mixed with cold water. The alignate is spatulated on the forehead and allowed to flow gently down the face. Care has to be taken to avoid any entrapped air. As the alignate sets, sheets of shredded thin cotton are placed on the unset alignate, allowing them to embed. A second layer of alignate is now placed on top. Again care has to be taken to avoid any air bubbles. After putting more thin sheets of cotton, a slurry of fast-set plaster and water is used with plaster gauze to adhere to the alignate. This gives the alignate a backing that prevents distortion once the impression is removed from the patient's face. Two to three layers of the gauze may be needed for sufficient stiffness. Often the weight of the gauze with plaster may cause the alignate to distort, thus reducing the accuracy of the impression.

Once the plaster has set, the patient, who has had the face covered for around $15 \mathrm{~min}$, has to lean forwards and move facial muscles to allow for release of the suction between the skin and the alignate. In this position, maximum distress is caused to the patient. The face needs to be cleaned very carefully in order not to break the skin, removing any petroleum jelly on eyelashes and cold cream on eyebrows.

The impression needs to be kept moist to avoid any distortion. Dental stone is used to cast a model of the patient's face by first blocking off the air passage and coating the surface with petroleum jelly to prevent the dental stone from bonding with the plaster gauze.

This process is still followed in most maxillofacial departments [3]. The major disadvantage to this method is the discomfort to the patient, the number of patient visits and time spent by the patient, and in turn the cost [4].

The idea of combining computer imaging of the human body with rapid manufacturing to have an integrated manufacturing system for maxillofacial use was initially conceived for biodegradable composites. Imaging techniques reported included stereophotogrammetry and moiré contourography [5-8], ultrasonography [6], conventional axial computed tomography (CT), magnetic resonance imaging (MRI) [9], lateral facial plates [10], facial plethysmography $[\mathbf{1 1}, 12]$, surface radiography [12], and laser surface scanners $[\mathbf{1 3}, \mathbf{1 4}]$. Stereophotogrammetry, moiré contourography, and MRI are accurate and reproducible but very expensive to run, while CT exposes the patient to unwanted radiation. Surface laser scanners have the advantage of being relatively inexpensive, fast, accurate, non-invasive, non-contact, and non-ionizing [13-17]. They consist of a low-power laser beam which is moved along the face to be scanned and is followed from an offset angle by a video camera that calculates the coordinates of the surface by triangulation and saves the data to a computer. Rapid manufacturing equipment is able to use these data after processing to form threedimensional objects by additions of layers of material [18]. These manufactured objects are thus custom designed for the patient but are engineered as compared with craft-based models made by traditional methods.

\section{EXPERIMENTAL TECHNIQUE}

The case studies presented here are for two patients who were referred to the Maxillofacial Department (Queens Medical Centre, Nottingham, UK) for making an ear prosthesis and a burns mask respectively. Real patients have been used in order to understand the underlying manufacturing technology issues.

\subsection{Case study I: ear prosthesis}

A 15-year-old girl had been referred for a left ear prosthesis (Fig. 1(a)) due to congenital absence. Two
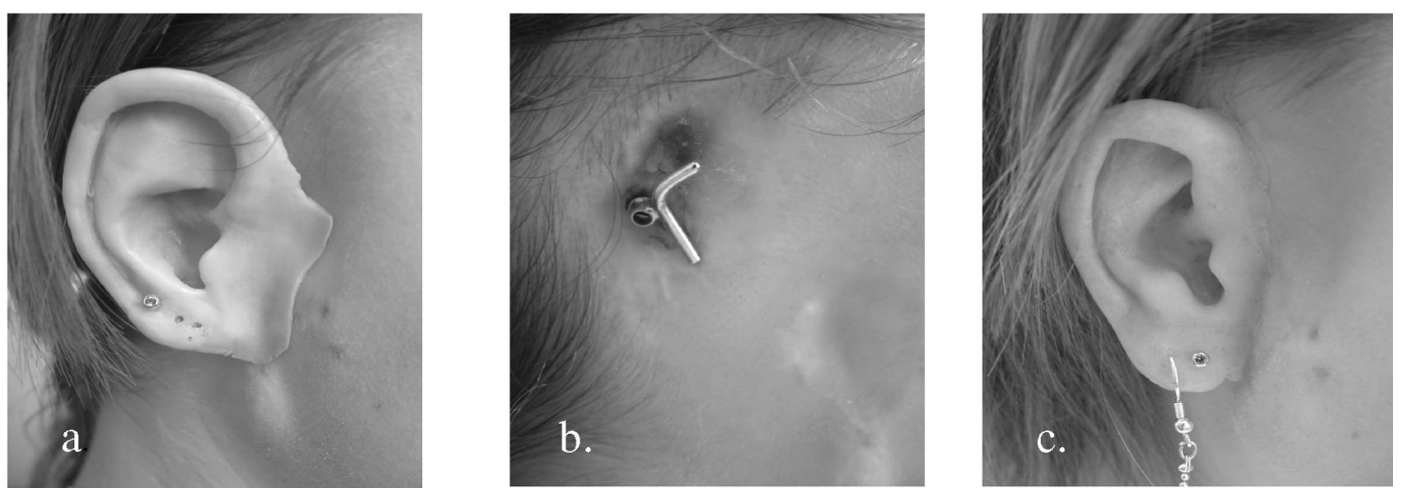

Fig. 1 Ear prosthesis patient: (a) old prosthesis; (b) ear implant with retention bar; (c) new prosthesis with the aid of rapid manufacturing 


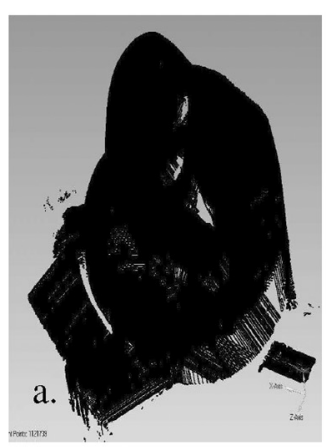

Points: $1,121,739$

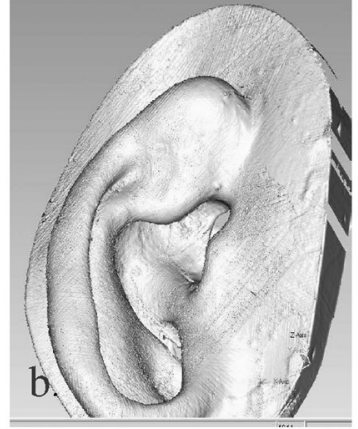

Points reduced to 458,566

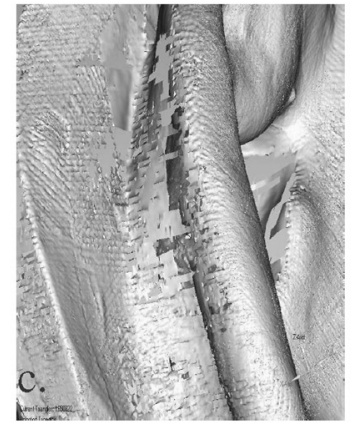

Patches: 4568

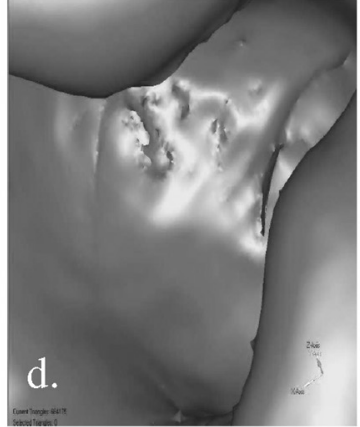

Triangles: 834,220

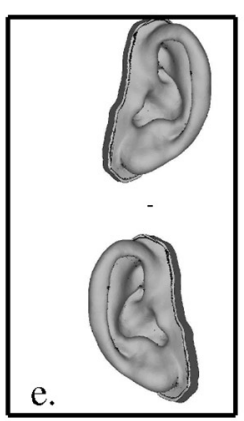

Triangles: $1,306,998$

Fig. 2 Manipulation of scanned data for ears: (a) initial cloud point data; (b) rough patch on cloud point data; (c) holes in the patches; (d) holes filled to leave rough surfaces; (e) mirror-imaged ears

Branemark implants [19] were placed into the temporal bone 4 years previously at another hospital and the prosthesis retained using a gold bar and clips (Fig. 1(b)). No review of the implants of prosthesis provided had been carried out post-operatively for 3 years. The prosthesis was in poor condition.

An impression was taken of her remaining ear, and a model cast and scanned using an inexpensive portable digital scanner (Polhemus FastScan ${ }^{\circledR}$ Digital Scanner) to produce a cloud point image of her ear. Using Raindrop Geomagic ${ }^{\circledR} 6.0$ software the cloud point data having over a million data points were reduced to around half of those retaining the general shape of the ear. The cloud of points was surfaced with 4568 patches and 834220 triangles, thickened, and mirror imaged (Fig. 2) to obtain a wax ear by the process of rapid manufacturing using a Thermojet machine (Wax 3D Printing Thermojet from 3D Systems). The wax ear was then adapted to the retention bar and clinically tried. The time spent with the patient to finish the sculpted ear was greatly reduced; however, the number of clinical stages remained the same. The prosthesis was adapted to the patient in the usual manner [2] and a final mould constructed and packed with medical-grade silicone elastomer to form the prosthesis. Figure 1(c) shows the finished prosthesis fitted to the patient.

\subsection{Case study II: burns mask}

A 24-year-old male suffered from a road traffic accident in which he burnt his head, arms, back, and chest. He was referred to the Maxillofacial Department for the construction of a burns mask [20]. The patient's burns were covered with skin grafting including multiple grafts on the scalp. He suffered from a chronic folliculitis in the non-grafted scalp which led to breakdown of his scalp and was diagnosed with erosive pustular dermatosis. Skin swabs showed the patient was methicillin-resistant Staphylococcus aureus positive and, because of this, contact with skin was to be limited. This ruled out the traditional method of making splint masks by taking impressions of his face. As in the previous case study, an inexpensive portable digital scanner (Polhemus FastScan ${ }^{\circledR}$ Digital Scanner) was used to capture an image of the patient's face, and cloud point data were collected and manipulated to be saved in the STL format (Fig. 3), which is the standard for rapid prototyping (RP) machines [21].

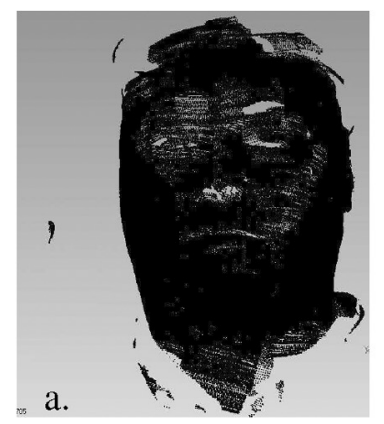

Points: 338,210

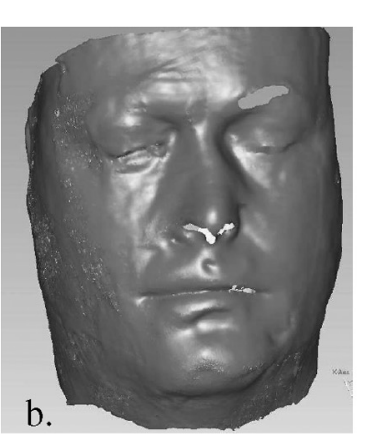

Triangles:281,790
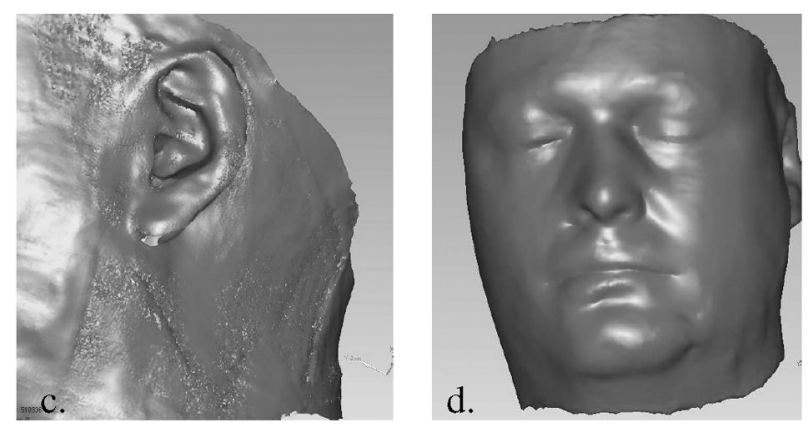

Fig. 3 Manipulation of scanned data for a splint: (a) initial cloud point data; (b) rough patch on cloud point data; (c) holes filled to leave rough surface; (d) smooth surface by cutting and filling 

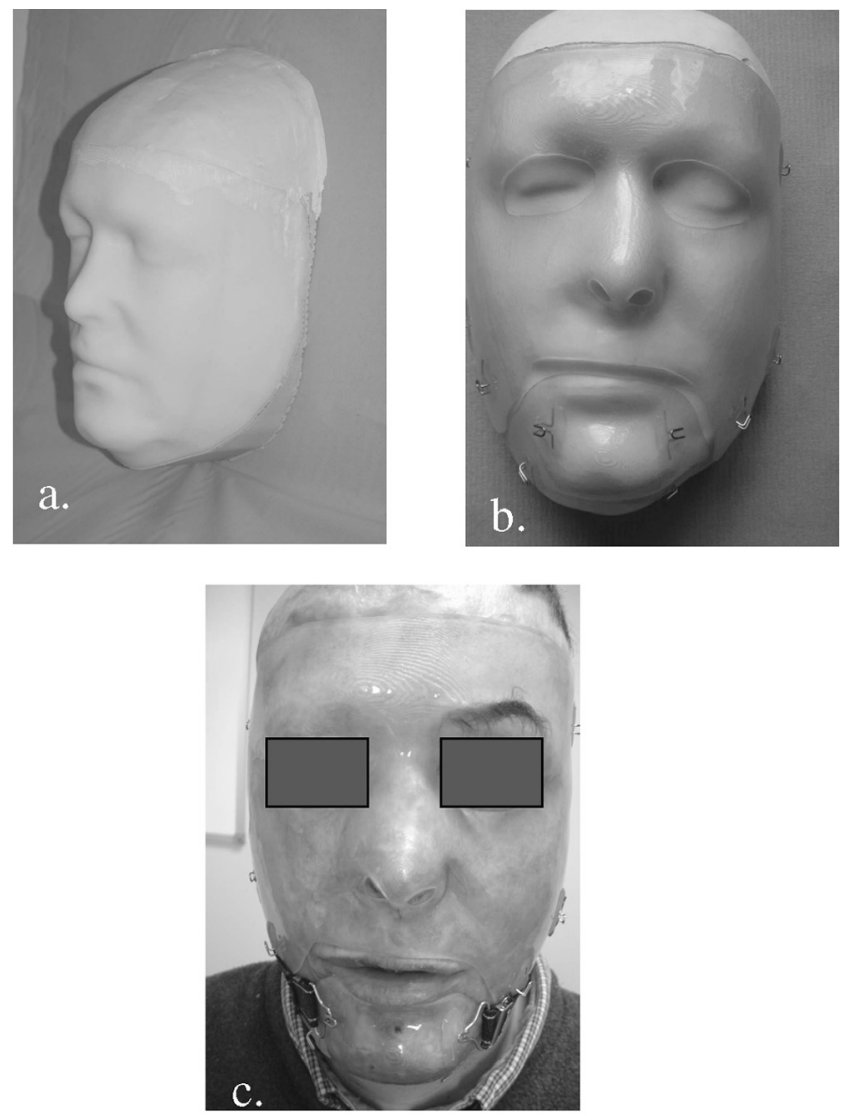

Fig. 4 (a) Impression of the patient's face made by FDM in acrylonitrile-butadiene-styrene copolymer; (b) mask made of PC fitting on the impression; (c) patient wearing the mask

The process involved using Raindrop Geomagic ${ }^{\circledR} 6.0$ software to reduce the data points to 338228 points, covering them with patches and triangles. Figure 3 shows the manipulation of data for the splint. Figure 4(a) shows the impression printed by the rapid manufacturing process of fused deposition modelling (FDM) in acrylonitrile-butadiene-styrene copolymer.

Vacuum thermoforming is a common shaping method in polymer industries and is usually used in the food packaging industry. The conventional process of making burns splints also uses it. A thermoplastic sheet of polycarbonate (PC) of thickness $3 \mathrm{~mm}$ was used to make the mask. The impression of the patient's head made by FDM was used as the mould. The mould was placed on to a platform with the PC sheet fixed over it. The PC sheet was initially heated by electric heaters to reach its softening point. Then the PC sheet was formed against the contours of the mould moving the platform to the sheet. Vacuum was applied to obtain a close impression of the sheet on the mould. The sheet was allowed to cool and the mould knocked out of the sheet, leaving the impression behind.
The mask was made by cutting the impression of the face out as seen in Fig. 4(b). The mask was divided into two parts to allow for movement of the jaw. Holes were cut for the eyes and mouth. Hooks were fashioned out of metal and adhered by heat, and straps were designed to hold the splint firmly to the patient's face.

\section{DISCUSSION}

In the case of the ear prosthesis patient, despite the old poor aesthetics of the prosthesis and unhappiness with it, the patient continued to wear it daily. She was initially unaware of the possibility of improvements as demonstrated by the revised process. The Thermojet wax was found to be compatible with the conventional prosthesis manufacture process. It is, however, a more refractory wax than the dental waxes commonly used and further development of a custom wax would be beneficial. The use of RP technology did not reduce the length of time that the patient had to wait for the prosthesis as a result of transfer of the data, file manipulation, and RP production time. Improvements can be made to this process.

Figure 4(c) shows the burns patient wearing the splint. Immediately on application of the splint, a blanching of the skin in all parts of the face was seen. This showed that the mask was having the required effect of reducing blood flow to the scars as is seen in perfectly fitting burns masks. In this case, the mask was manufactured in one sitting for the patient. In the conventional process as seen in Fig. 5, the fitting of the manufactured mask on the patient is an iterative process. If the fit of the splint is not as desired, then the stone mould made of the patient's head and face needs modification with a new splint being made from the modified stone. This skill-based 'cut-and-try' process is performed by 'eye' using the operator's experience and splint manufacture repeated for as many times as it takes to obtain a useful fit of the mask. This is a timeconsuming process and much material is wasted. The patient has many sittings, usually requiring an outpatient or clinic visit, until the splint fits. Often because the features of the patient are not followed as closely in the burns splint created by the old process, the pressure exerted on the scars is insufficient and not uniform, leading to increased healing time and thus further prolonging the process for the patient. This patient had previously had three traditionally made splints which were all unsuccessful because of poor fit. Figure 6 shows the flow chart of the process when using RP technology which has only one decision and reduces the number of steps from 34 to 17 . 


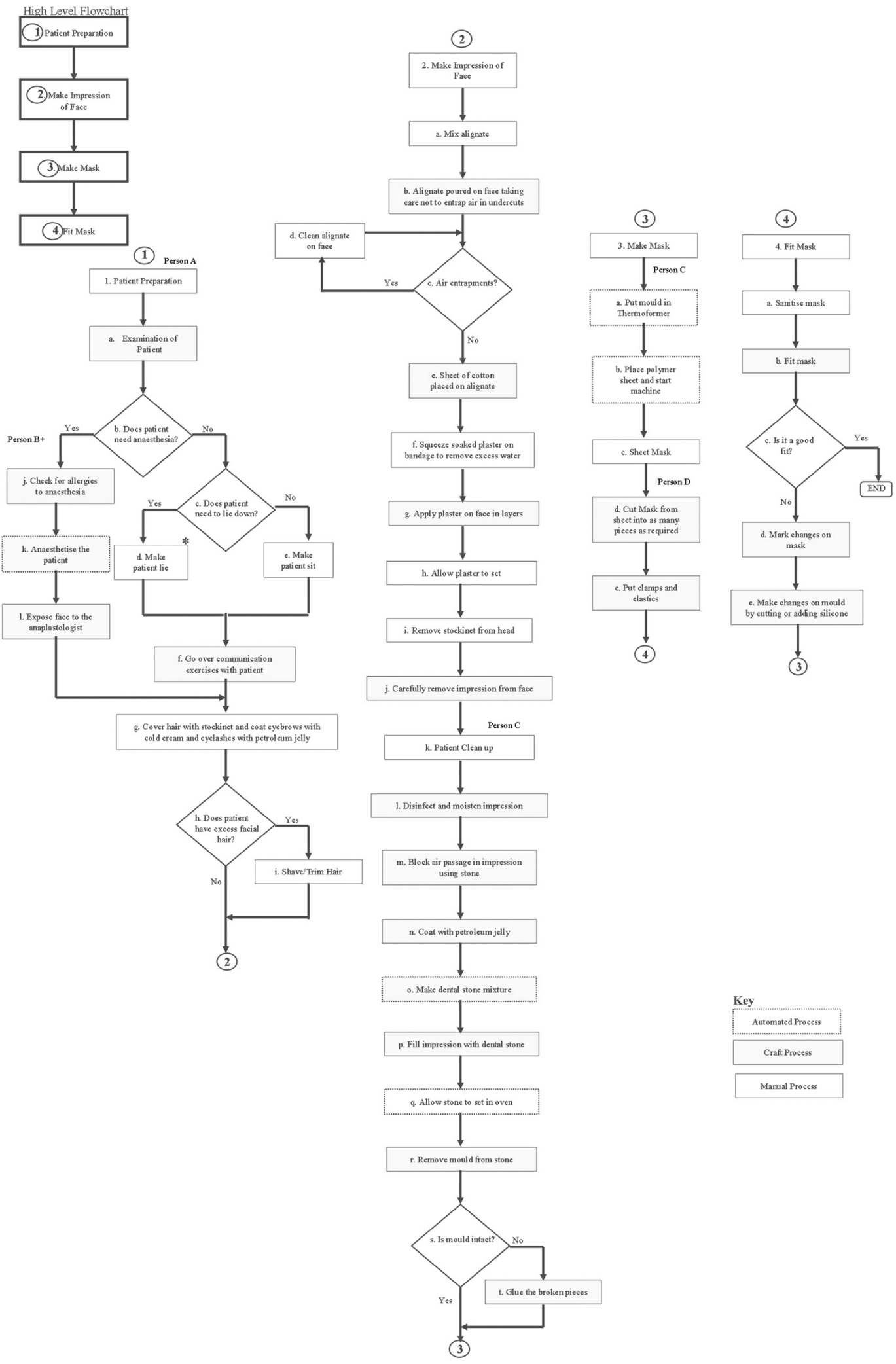

Fig. 5 Process flow chart of the conventional process of making a burns splint. Normally the seating position is preferred. If a lying-down position is used because the patient cannot sit that long, the impression will be distorted owing to the effect of gravity on the face. Step 4 may then have to be repeated a few times to obtain a perfect fit 


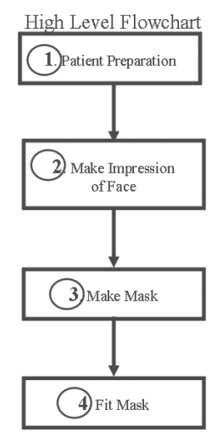

(1)

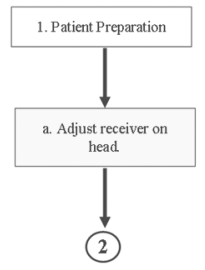

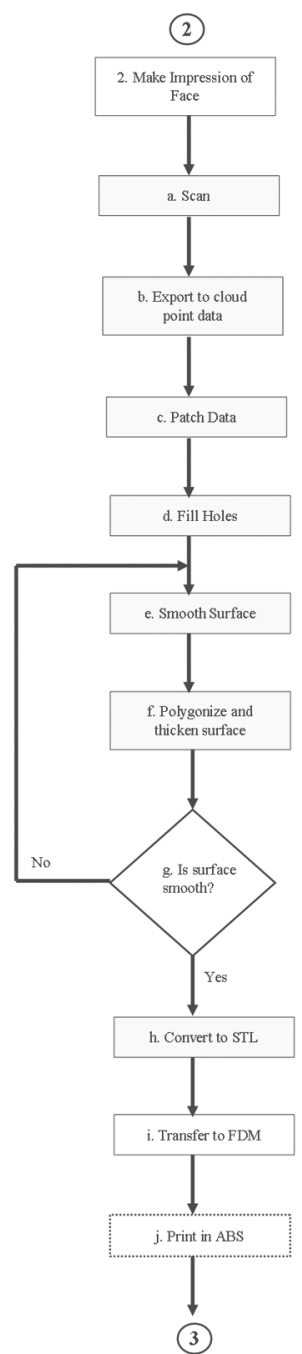

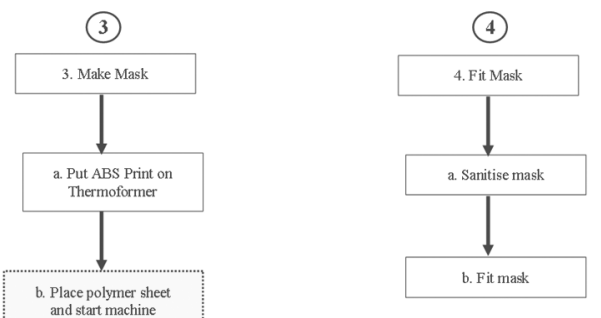

..................................

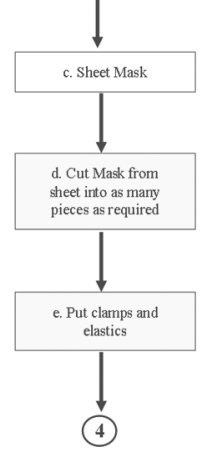

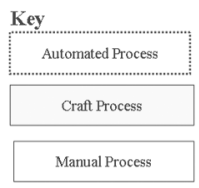

Fig. 6 Flow chart for the novel process of making a burns splint using laser scanning and rapid manufacturing

\section{CONCLUSIONS}

Both case studies used a compact low-cost laser scanner to capture facial geometry followed by rapid manufacturing to obtain intermediary products which were used for shaping final maxillofacial products. In both cases, the aim of converting a craft-based process into an engineering-based manufacturing process was achieved. Initial feedback from both clinicians and patients has been positive.

Additional work is required to streamline the process of manipulating the computer-aided design cloud point data, this includes modifications to the path of the wand when collecting data, improved 
selection of scanner resolution to match the minimum data requirement, and algorithms to extract surfaces from the cloud point data perhaps by automating the steps of clearing of rough patches. Further clinical work will address the construction of radio therapy masks.

\section{REFERENCES}

1 Johnston, V. S., Solomon, C. J., Gibson, S. J., and Pallares-Bejarano, A. Human facial beauty - current theories and methodology. Arch. Facial Plastic Surg., 2003, 5, 371-377.

2 McKinstry, R. E. Fundamentals of Facial Prosthetics, 1995 (ABI Professional Publications, Arlington, Virginia).

3 Braiser, S. (ed.) Maxillofacial Laboratory Techniques, 1954, pp. 164-169 (Kimpton, London).

4 King, G. E. Maxillofacial prosthetic rehabilitation. J. Oral Surg., 1971, 29, 805-811.

5 Breytenbach, H. S. Objective measurement of postoperative swelling. Int. J. Oral Maxillofacial Surg., 1978, 7, 386-392.

6 Troullos, E. S., Hargreaves, K. M., Butler, D. P., and Dionne, R. A. Comparison of nonsteroidal antiinflammatory drugs, ibuprofen and fluriprofen, with methylprednisolone and placebo for acute pain, swelling, and trismus. J. Oral Maxillofacial Surg., 1990, 48, 945-952.

7 Ucok, C. Stereophotogrammetric assessment of the effect of tenoxicam on facial swelling subsequent to third molar surgery. Int. J. Oral Maxillofacial Surg., 1997, 26, 380-382.

8 Beirne, O. R. and Hollander, B. The effect of methylprednisolone on pain, trismus, and swelling after removal of third molars. Oral Surg. Oral Medicine Oral Pathology, 1986, 61, 134-138.

9 Schaberg, S. J., Stuller, C. B., and Edwards, S. M. Effect of methylprednisolone on swelling after orthognathic surgery. J. Oral Maxillofacial Surg., 1984, 42, 356-361.

10 ElHag, M., Coghlan, K., Christmas, P., Harvey, W., and Harris, M. The anti-inflammatory effects of dexamethasone and therapeutic ultrasound in oral surgery. Br. J. Oral Maxillofacial Surg., 1985, 23(1), $17-23$.

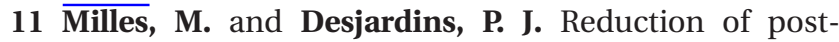
operative facial swelling by low-dose methylprednisolone. J. Oral Maxillofacial Surg., 1993, 51, 987-991.

12 Milles, M., Desjardins, P. J., and Pawel, H. E. The facial plethysmograph: A new instrument to measure facial swelling volumetrically. J. Oral Maxillofacial Surg., 1985, 43, 346-352.

13 Arridge, S., Moss, J. P., Linney, A. D., and James, D. Three dimensional digitisation of the face and skull. J. Maxillofacial Surg., 1985, 13, 136-139.

14 Moss, J. P., Linney, A. D., Grindrod, S. R., and Mosse, C. A. A laser scanning system for the measurement of facial surface morphology. Optics Lasers Engng, 1989, 10, 179-190.

15 Nixon, M. A. Laser scanning for three dimensional imaging of the body surface. Thesis for the degree of Bachelor of Medical Science, University of Otago, Otago, New Zealand, 1995.

16 Wilson, I., Snape, L., Fright, W. R., and Nixon, M. A. An investigation of scanning techniques for quantifying changes in facial soft tissue volume. N.Z. Dent J., 1997, 93, 110-113.

17 Fright, W. R., Oien, N. A., Price, N. B., Martin, C. B., and Tremewan, R. N. Boxy surface laser profile scanner. In Proceedings of the 7th New Zealand Image Processing Workshop (Ed. P. J. Bones), Christchurch, New Zealand, August 1992, pp. 83-87 (UniPrint, Auckland, New Zealand).

18 Chua, C. K., Jacob, G. G. K., and Mei, T. Interface between CAD and rapid prototyping systems. Part 1: a study of existing interfaces. Int. J. Advd Mfg Technol., 1997, 13, 566-570.

19 Adell, R., Eriksson, B., Lekholm, U., Branemark, P.-I., and Jemt, T. A long-term follow-up study of osseointegrated implants in the treatment of the totally edentulous jaw. Int. J. Oral Maxillofacial Implants, 1990, 5(4), 347-359.

20 Jordan, R. B., Daher, J., and Wasil, K. Splints and scar management for acute and reconstructive burn care. Clinics Plastic Surg., 2000, 27, 71-85.

21 Chua, C. K. and Leong, K. F. Rapid Prototyping: Principles and Applications in Manufacturing, 1997 (John Wiley, Chichester, West Sussex). 